\title{
The Effect of Metacognitive Teaching Method on Student's Conceptual and Procedural Problem Solving Ability in Engineering Mathematics
}

\author{
Shihab Mohammed Salih Hasan, Woria Soltanian* and Haideh Ghaderi \\ Department of Mathematics, Faculty of Education, Soran University, Kurdistan Region, Iraq; \\ shihabsalih@yahoo.com, Baten_2921@yahoo.com, haideh.ghaderi@gmail.com
}

\begin{abstract}
Objectives: To investigate the effect of metacognitive teaching method on student's conceptual and procedural problem solving ability in engineering mathematics. Method: Population of this study was 53 engineering students that they were select engineering mathematics in first semester of 2018 in Kurdistan. The population of this study as two groups were randomly selected and divided as control group that received traditional (discourse) teaching method and the experimental group had their lessons based on metacognitive approach. The data were analyzed via T-test and LSD. Finding: The results showed, first, metacognitive teaching is more effective than traditional method in teaching engineering mathematics; second, there was significant difference between ability of solving conceptual problems of two groups, but there was no difference on procedural problems. Implementation: Research indicates that using psychological skills in teaching plays an essential part in the learner's ability to solve problems; however this is not the case with engineering sciences, where little emphasis is given to psychological factors in learning. The present study will open up new horizons to the researchers in this field of study. The results of this study suggest to teachers that allocate special place to methods teachings that created based on constructivism philosophy. Also teachers should try to create active learning environmental until students can enjoy learning mathematics.
\end{abstract}

Keywords: Conceptual and Procedural, Engineering, Metacognitive Teaching, Problem Solving

\section{Introduction}

During the last decade, considerable interest has been paid to the design of constructivistic learning environments. Constructivist educational sketching aims to supply active and creatively mental construction "tool kits" embedded in relevant learning environments that facilitate science construction by learners. Compared to ancient educational systems approaches of sketching instruction, constructivism makes a special set of assumptions concerning learning and suggests new educational principles $\stackrel{1}{\text {. }}$.

Metacognition is rooted from strong theoretical and empirical ideas assumptions that some of its basic theories can be found in developmental cognitive psychology. According to Peugeot's view, learners find relationship or association between aims, means, metacognitive experiences and output of learning cases and then adapt or adjust their own observation with resultant observation. Furthermore, the basic principle of the above mentioned psychology can be found in Bruner theory. He likens human mind to a machine which uses existing knowledge to reinterpreting and reorganizing new and past information 2 . The term of metacognition was first used in 1976 by Flavell, especially in the field of memory. He defines metacognition as cognition about cognition, or in general, knowledge and control of cognition. Ever since different specialists have applied this term in various

${ }^{*}$ Author for correspondence 
disciplines such as artificial intelligence, conception, information processing, social learning, mathematics and so on ${ }^{3}$.

Some definition about metacognition are in literature; if you are aware of existing monologue in your mind, and if you are familiar with decision-making and problem solving processes, then you'll experience metacognition. Also metacognition is a person's ability to identify and recognize his own knowledge or ignorance. He added that if teachers focus on thinking about thinking, the students may acquire association and conception and conception of mind processing ${ }^{4}$. Although new findings have categorized metacognition as metacognitive knowledge and metacognitive control ${ }^{5,6}$ Flavell and teammate hold that, metacognition includes three components of, metacognitive knowledge, metacognitive monitoring and self regulation?

Metacognitive knowledge is the person's information and awareness about the world which is saved in long-term memory in the long time and does not relate to a specific subject. This kind of knowledge includes two sub-categories of factual knowledge and strategically knowledge. The former relates to a person's knowledge about obligation, strategies and himself and the latter consists of a person's knowledge about the how and quality of using the strategy of problem solving. Metacognitive knowledge about oneself is the extent of a person's knowledge of his or her capability to do a task successfully. Metacognitive knowledge about obligation includes a person's knowledge about difficulty or easiness of different parts of a task or activity. Strategic knowledge is the person's awareness of given strategies and skills to do the tasks. In addition, by strategic knowledge, we mean the person's information and awareness about learning strategy and situational condition of their application will help the students to choose the strategies that are more efficient. Another component is metacognitive monitoring by which we mean having a planer program to watch or monitor doing the tasks and considering their accuracy or inaccuracy. In this part, the skilful learners prove whatever they have learned, show that about what subjects they are approaching proficiency and in what area they require further effort. The process of monitoring and analyzing accuracy or inaccuracy of responses may require the person to review and complement subject matter and used strategies. Self-regulation component is applied to stable metacognitive adjustments and optimization, which are presented on the part of the learner against feedback to possible errors or mistakes. Self-regulating skill has a function like error-finding and directing the behavior of problem solving. Both metacognitive monitoring and self regulation offer the person information about the rate and extent of his progress, and directs his activities in achieving the solution to the tasks or efficient performance in a specific situation. These three components are strongly interrelated, for example, when a person's metacognition is limited in a given task, this knowledge may lead to more monitoring and care on doing the task. Furthermore, if a person comes across many errors in monitoring, he will conclude that given task is very difficult or he does not have ability in this specific area $\stackrel{8}{\text {. }}$.

Schoenfeld believes that if mathematics education emphasizes purely on base knowledge and problem solving strategies, it has applied only a small part of mathematics thinking. According to Schoenfeld, in math syllabus, both cognitive and metacognitive strategies should be included. So far, in mathematics education more emphasis has been put on transferring of the content of mathematics knowledge to students and less emphasis is metacognition factor ${ }^{\text {? }}$.

It has already been discerned that mathematics is a vita discipline attributable to its sensible role to the individual and society. Through a problem-solving approach, this facet of math wills is developed. Developing necessary skills for solving a problem is more important and exciting than teaching the skills without a context. Such action provides problem solving special value as a important factor for learning new concepts and skills ${ }^{10}$. A part from being a subject of study, mathematics is a way of thinking that is formed based on understanding capability and presenting problem dimensions explaining underlying concepts of problem, classifying the required information and explicating ways of problem solving. In the traditional syllabus and common teaching of mathematics, This discipline is considered just as a collection of facts and procedures which learners are required to know it in a parrot- fashion way. But in new approaches of teaching, emphasis is put on aims such as comprehension, creating relationship between conceptions and mathematical reasoning, and using of heuristic (discovering) process of problem solving in order to enhance and expand strategic and conceptual knowledge of the students. These purposes are on part with training the students who are "self-directed" "self-responsible" and "self-regulated". 
These aims may not be achieved simply and can't have limited and short-term consequences ${ }^{11}$.

Most of the students have ability to learn the necessary formulas and their application only in limited scope of the textbooks and exam conditions, but face many problems upon encountering new problems and have shown that they are unable to understand deeply the concepts and their relationship. Problem solving is an important component of mathematics education because it is the single vehicle which seems to be able to achieve at school level all three of the values of mathematics listed at the outset of this article: functional, logical and aesthetic. Let us consider how problem solving is a useful medium for each of these ${ }^{12}$.

The teachers with little or no metacognitive skills put the blame on the students as one of the factors that paralyze them on encountering complex and problem solving situation believe that people with too much metacognitive ability are meticulous about understanding the relations between problem facts, analyze their own way of problem solving, analyze complex problems in more detailed ways and control their own way of thinking by self-asking. Some researchers pointed out there is difference between having metacognitive skills and making an efficient use of them. Failure to do a reasonable obligation, often results from misplaced or incomplete use of cognitive and metacognitive skills rather than lack of its peripheral knowledge $\mathrm{e}^{13}$.

\section{Method of Research}

Population of this study was 53 engineering students that they were select engineering mathematics in first semester of 2018 in Kurdistan. The subjects were available and divided into two groups. 27 students were placed in experimental group and 26 others were placed in control group. In this study the researcher who was also the teacher, was teaching the control group in traditional (discourse) and teaching to experimental group was based on following techniques: Working in small groups of learning; General discussion in the classroom; Teacher as a model role for metacognitive behavior.

In this study, for measuring of conceptual and procedural problem solving ability, three mathematical tests include conceptual and procedural problems were conducted on students in both groups. Test I after one month, test II after two months, and test III after three months. Each test was including two parts of conceptual and procedural problems. Also the same final mathematics tests that include six problems (three conceptual and three procedural) was criterion of performance in each group. In this study, for analysis of data, we used T- test, LSD test, and descriptive statistics.

\section{Results and Analysis}

As mentioned above, three mathematics tests conducted on students in both group during three months. At first, results of conceptual problems solving in two groups of metacognitive and traditional are provided. The results showed that in test $\mathrm{I}$, the scores mean on students in metacognitive group was more than traditional group, but didn't find significant difference. But in test II, III the scores mean on students in metacognitive group was more than traditional group, and this difference was significant. The results are shown in Table 1.

The results of procedural problems solving in two groups are provided in Table 2 . The results showed that in test I, II the scores mean on students in metacognitive group was more than traditional group, but didn't find significant difference. In test III, the scores mean on students in metacognitive group was more than traditional group and this difference was significant. The results are shown in Table 2.

Table 1. The results of T-test for compare of conceptual problem solving in both groups

\begin{tabular}{|c|c|c|c|c|c|c|c|}
\hline Test & Groups & $\mathbf{n}$ & Mean & S.D & $\mathbf{t}$ & df & Sig \\
\hline \multirow{2}{*}{ Test I } & Metacognitive & 27 & 15.24 & 4.13 & \multirow{2}{*}{0.43} & \multirow{2}{*}{51} & \multirow{2}{*}{$\mathrm{P}=0.42$} \\
\hline & Traditional & 26 & 15.39 & 5.47 & & & \\
\hline \multirow{2}{*}{ Test II } & Metacognitive & 27 & 14.98 & 6.23 & \multirow{2}{*}{1.79} & \multirow{2}{*}{51} & \multirow{2}{*}{$P=0.04$} \\
\hline & Traditional & 26 & 14.15 & 6.80 & & & \\
\hline \multirow{2}{*}{ Test III } & Metacognitive & 27 & 15.09 & 8.25 & \multirow{2}{*}{1.98} & \multirow{2}{*}{51} & \multirow{2}{*}{$\mathrm{P}=0.03$} \\
\hline & Traditional & 26 & 14.13 & 7.56 & & & \\
\hline
\end{tabular}


Table 2. The results of T-test for compare of procedural problem solving in both groups

\begin{tabular}{|c|c|c|c|c|c|c|c|}
\hline Test & Groups & $\mathbf{n}$ & Mean & S.D & $\mathbf{t}$ & df & Sig \\
\hline \multirow{2}{*}{ Test I } & Metacognitive & 27 & 17.46 & 5.17 & \multirow{2}{*}{0.29} & \multirow{2}{*}{51} & \multirow{2}{*}{$\mathrm{P}=0.37$} \\
\hline & Traditional & 26 & 17.29 & 5.96 & & & \\
\hline \multirow{2}{*}{ Test II } & Metacognitive & 27 & 16.84 & 7.27 & \multirow{2}{*}{0.51} & \multirow{2}{*}{51} & \multirow{2}{*}{$\mathrm{P}=0.32$} \\
\hline & Traditional & 26 & 16.67 & 5.13 & & & \\
\hline \multirow{2}{*}{ Test III } & Metacognitive & 27 & 18.21 & 6.25 & \multirow{2}{*}{1.71} & \multirow{2}{*}{51} & \multirow{2}{*}{$\mathrm{P}=0.045$} \\
\hline & Traditional & 26 & 17.51 & 7.58 & & & \\
\hline
\end{tabular}

In Table 3, the results of final performance test of the students in both groups- which was similar and simultaneous- was analyzed by using T-test. It must be noted that student's scores was calculated based on 20 .

The results shows that the mean difference of performance score of students in both

Table 3. Results of T-test for compare of math test scores means between two groups after three months

\begin{tabular}{|c|c|c|c|c|c|c|}
\hline Groups & N & Mean & SD & t & df & Sig \\
\hline Metacognitive & 27 & 15.74 & 6.60 & \multirow{2}{*}{2.18} & 51 & 0.021 \\
\hline Traditional & 26 & 14.69 & 7.32 & & & \\
\hline
\end{tabular}

groups has significant difference at level $(t[51]=2.18, p=0.021)$. In fact, the only effective factor on performance of students in metacognitive group was metacognitive teaching method. The result of LSD test for performance on three mathematics tests for the metacognitive group showed that, there wasn't a significant difference between test I and test II. But the results showed there is a significant difference between tests III with other two tests. The results are shown in Table 4. The result of LSD test for performance on three mathematics tests for the traditional group showed that, there wasn't a significant difference between each three tests. The results are shown in Table 5.

Table 4. The results of LSD test between three tests for performance of metacognitive group

\begin{tabular}{|c|c|c|c|c|c|c|}
\hline \multirow{2}{*}{ Tests } & & \multirow{2}{*}{ Mean Difference } & \multirow{2}{*}{ Std. Error } & \multirow{2}{*}{ Sig. } & \multicolumn{2}{|c|}{ 95\% Confidence Interval } \\
\hline & & & & & Lower Bound & Upper Bound \\
\hline \multirow{2}{*}{ I } & II & .31 & .745 & .17 & -.57 & .63 \\
\hline & III & -.35 & .563 & .11 & -.72 & .99 \\
\hline \multirow{2}{*}{ II } & $\mathrm{I}$ & .31 & .745 & .17 & -.63 & .57 \\
\hline & III & -.58 & .613 & .1 & -1.08 & .63 \\
\hline \multirow{2}{*}{ III } & I & .35 & .563 & .11 & -.99 & .72 \\
\hline & II & .58 & .613 & .1 & -.63 & 1.08 \\
\hline
\end{tabular}

Table 5. The results of LSD test between three

\begin{tabular}{|c|c|c|c|c|c|c|}
\hline \multirow{2}{*}{ Tests } & \multirow{2}{*}{ Mean Difference } & \multirow{2}{*}{ Std. Error } & \multirow{2}{*}{ Sig. } & \multicolumn{2}{|c|}{ 95\% Confidence Interval } \\
\cline { 5 - 7 } & & & & & Lower Bound & Upper Bound \\
\hline \multirow{2}{*}{ I } & II & -0.53 & .315 & .09 & -1.324 & .661 \\
\cline { 2 - 7 } & III & $1.49^{*}$ & .563 & .02 & -2.54 & -.67 \\
\hline \multirow{2}{*}{ II } & I & 0.53 & .315 & .1 & .661 & -1.324 \\
\cline { 2 - 7 } & III & $-1.35^{*}$ & .369 & .03 & -2.36 & -.83 \\
\hline \multirow{2}{*}{ III } & I & $1.49^{*}$ & .563 & .02 & .97 & 2.54 \\
\cline { 2 - 6 } & II & $1.35^{*}$ & .369 & .03 & .83 & 2.36 \\
\hline
\end{tabular}




\section{Conclusion}

The metacognitive teaching method has a great impact on students' performance in solving of conceptual problems. The results showed that metacognitive teaching doesn't have impressive impact on solving procedural problems and there wasn't significance difference between metacognitive and traditional groups.

Also the results of LSD test showed that metacognitive teaching method have impact on performance of students in midterm. In the other hand, there wasn't significance difference between tests I and II. But after three months of applying metacognitive method, performance of students in final exam and test III was more than two prior tests and their difference was significant.

Also the result showed that in solving of procedural problems in test III, there existed difference between metacognitive and rational groups and this difference was attributed to the benefit of metacognitive group.

\section{Discussion and Implementation}

Researchers believe that if mathematics education emphasizes purely on base knowledge and problem solving strategies, it has applied only a small part of mathematics thinking. According to Schoenfeld, in math syllabus, both cognitive and metacognitive strategies should be included. So far, in mathematics education more emphasis has been put on transferring of the content of mathematics knowledge to students and less emphasis is metacognition factor?

In the process of problem solving, behaviors may be influenced by various kinds of beliefs and attitudes. For instance, a person's belief and attitude toward school nature and, in general, mathematics and its learning, mathematics specific task, and the person's mathematic ability can have a role in person's response to a problem solving situation ${ }^{14}$.

Given many years of teaching experience of the researchers of this study in applying metacognitive teaching, they recommend those lecturers and teachers who want to use on apply this method. The main point is that learners should be prepared mentally and active, participating and interacting environment should be created between teachers and learners. The lecturers and teachers should have full knowledge over application of those kinds of teaching methods and by setting appealing and challenging problems and at the right level of student's knowledge and ability, encourage them to work on mathematic problems. The lecturers or teachers should also have confidence and belief in effectiveness of his or her own way of teaching and transmit this belief to the learners.

\section{Reference}

1. Karagiorgi Y, Symeou L. Translating Constructivism into Instructional Design: Potential and Limitations, Educational Technology and Society. 2005; 8(1):17-27.

2. Aghazadeh M, Ahadian M. Theoretical framework and pedagogical applications of metacognition. Noorpardazan press, Iran; 2008.

3. Flavell GH. Metacognition and Cognitive Monitoring: A new area of psychological inquiry, American Psychologist. 1976; 34:906-11. $\quad$ https://doi.org/10.1037//0003066X.34.10.906.

4. Costa LA. Mediating the Metacognitive, Educational Leadership. 1984; 3(2):57-62.

5. Otani H, Widner RL. Metacognition: New issues and approaches, The Journal of General Psychology. 2005; 132(4):329-34. https://doi.org/10.3200/GENP.132.4.329334.

6. Sungur S. Contribution of motivational beliefs and metacognition to students' performance under consequential and nonconsequential test conditions, Educational Research and Evaluation. 2007; 13(2):127-42. https://doi.org/10.1080/13803610701234898.

7. Flavell JH, Miller PH, Miller SA. Cognitive Development. 3, editor. Englewood Cliffs, NJ: Prentice Hall; 1993.

8. Boekaerts M. Self-regulated Learning: where we are today, International Journal of Educational Research. 1999; 31:445-57. https://doi.org/10.1016/S0883-0355(99) 00014-2.

9. Schoenfeld AH. Metacognition and mathematics education. USA: Pergamon press; 2006.

10. Mathematics NCoTo. Principles and standards for school mathematics. Reston, VA; 2000.

11. Peterson C. Self-Regulated Learning and Achievement of Senior Biology Students, Teacher Journal. 2013; 42(2).

12. Glasersfeld EV. Radical Constructivism. Learning AWoKa, editor. London: Falmer Press; 1995. https://doi. org/10.4324/9780203454220.

13. Bandura A. Self Efficacy: Exercise of Control. New York: H, W: Freeman and Company; 1997.

14. Gooya Z. Influences of Metacognition-Based Teaching and Teaching via Problem solving on student's beliefs about Mathematics and Mathematical problem solving, 1992; 23(4):37-49. 